\title{
Vivência de Familiares Sobre Visita de Crianças e Adolescentes em UTI Adulto
}

\author{
The Experience of Relatives About the Visits of Children and Adolescents to Adult UTI \\ Vivencia de Familiares Sobre la Visita de Niños y Adolescentes en la UTI de Adultos
}

\author{
Maria Emília Pereira Nunes ${ }^{1}$ \\ Letícia Macedo Gabarra \\ Universidade Federal de Santa Catarina
}

\begin{abstract}
Resumo
Esta pesquisa objetivou identificar a vivência de familiares em relação a comunicação, tomada de decisão e manejo da entrada de crianças e adolescentes para visitar os pacientes internados em UTI adulto. A abordagem deste estudo foi qualitativa. Foram realizadas entrevistas com 10 familiares de pacientes que estiveram internados em UTI. Os dados foram analisados de acordo com a análise de conteúdo de Bardin (2009), emergindo quatro categorias: Comunicação; Tomada de decisão sobre a visita; Manejo, e Repercussões da visita. A comunicação dos participantes com os menores foi aberta. A tomada de decisão dependeu da inter-relação entre o desejo de visitar, o estado do paciente, o imaginário da visita e o posicionamento da equipe. Em relação ao manejo, todos destacaram a importância da preparação prévisita. O estabelecimento de diretrizes claras nas instituições, assim como a capacitação dos profissionais acerca da visita de crianças, poderia contribuir para a prática em saúde.

Palavras-chave: Unidade de Terapia Intensiva, visitas a pacientes, criança, adolescente, relações profissional-família
\end{abstract}

\begin{abstract}
This research aimed to report the experience of family members regarding communication, decision making and management of entry of children and adolescents into adult UTIs to visit admitted patients. The approach of this study was qualitative. Interviews were conducted with ten family members of patients who were admitted to the UTI. Data were analyzed according to Bardin's content analysis (2009), from which four categories emerged: communication; decision-making about the visit; management of the visits; and repercussions of the visit. The communication of participants with the children and adolescents was open. Decision-making depended on the combination between factors such as the desire to visit the patient, the clinical status of the patient, the imaginary related to the visit in the UTI, and the positioning of the health team. As for the management of the visits, all participants highlighted the importance of preparation before the visit. The establishment of clear guidelines in institutions, as well as the training of professionals about the visit of children could contribute to the health practice.

Keywords: Intensive Care Unit, visit to patients, Children, adolescents, professional-family relations
\end{abstract}

\section{Resumen}

Esta investigación tuvo como objetivo identificar la experiencia de los miembros de la familia con respecto a la comunicación, toma de decisiones y gestión de la entrada de niños y adolescentes para visitar a los pacientes ingresados en UTI de adultos. El enfoque de este estudio fue cualitativo. Se llevaron a cabo entrevistas con diez familiares de pacientes ingresados en la UTI. Los datos fueron analizados según el análisis de contenido de Bardin (2009), emergiendo cuatro categorías: comunicación; toma de decisiones acerca de la visita; gestión del asunto y repercusiones de la visita. La comunicación de los participantes con los menores fue abierta. La toma de decisiones dependió de la interacción entre el deseo de visitar, el estado clínico del paciente, el imaginario de la visita y el posicionamiento del equipo. En relación con la gestión, todos hicieron hincapié en lo importante de la preparación antes de la visita. El establecimiento de directrices claras en las instituciones, así como la formación de los profesionales sobre la visita de los niños, podría contribuir a las buenas prácticas en salud.

Palabras clave: Unidad de Cuidados Intensivos, visita a pacientes, niño, adolescente, relaciones profesional-famili

\footnotetext{
${ }^{1}$ Endereço de contato: Rod. BR 101, km 201, 4161, ap. 73, bl. 5, Serraria, São José, SC, CEP 88115-100. E-mail: mariaemiliapn@gmail.com
} 


\section{Visita de crianças e adolescentes em UTI adulto: vivência de familiares}

Na Unidade de Terapia Intensiva (UTI), estão os pacientes em estado grave ou potencialmente grave, além dos recursos tecnológicos e humanos especializados disponíveis para seu tratamento. O adoecimento e a necessidade de hospitalização em UTI desencadeiam uma série de reações emocionais no paciente e em sua família, como tristeza, ansiedade e medo. Neste estudo, a família é compreendida a partir dos vínculos afetivos e do sentimento de pertença existente entre seus membros, podendo incluir ou não os laços de consanguinidade (Cerveny \& Berthoud, 2009). As crianças são capazes de perceber e buscam saber sobre as mudanças na dinâmica familiar (Sengik \& Ramos, 2013; Kean, 2009; Castro \& Piccinini, 2002; Torres, 1999). Este aspecto é corroborado pela pesquisa de Rozdilsky (2005), a qual evidenciou que as crianças demonstraram estar atentas à comunicação indireta e que, muitas vezes, essa é sua forma de conhecer mais sobre a doença, ou seja, elas percebem o que ocorre em sua família, observam as conversas dos adultos, assim como suas expressões faciais.

De qualquer forma, além dos adultos, crianças e adolescentes podem estar presentes na composição familiar dos pacientes internados e, assim como o restante da família, sofrem o impacto emocional de ter um familiar internado em UTI (Kean, 2009; Knutsson et al., 2008). Johnson (1994) aponta, inclusive, que crianças participativas do processo de adoecimento e hospitalização têm demonstrado, a partir dos familiares, o desejo de visitar seus entes hospitalizados.

A exclusão das crianças na comunicação acerca do processo do adoecimento e da hospitalização é apontada em diferentes estudos (Gabarra \& Crepaldi, 2011; Nova, Vegni, \& Moja, 2005; Armelin et al., 2005; Oliveira et al., 2004). A omissão ou a distorção da informação pode ocorrer pela dificuldade do adulto em informar claramente a criança ou o adolescente sobre a situação de saúde do familiar internado (Sengik \& Ramos, 2013), na tentativa de protegê-la do sofrimento emocional (Kean, 2009).

$\mathrm{Na}$ falta de comunicação sobre o que a criança percebe à sua volta, suas percepções permanecem carentes de significados e o intuito dos adultos de proteger a criança pode, inclusive, prejudicar o desenvolvimento emocional dela (Rozdilsky, 2005). O vínculo com a criança e a fala de forma gradativa, honesta, com linguagem simples e clara, podem facilitar a comunicação com a criança (Lima \& Kovacs, 2011; Gabarra \& Crepaldi, 2011). Assim, mesmo que a crianca possa achar a experiência assustadora, sintomas de ansiedade e os sentimentos relacionados ao abandono e ao medo da morte podem ser reduzidos à medida que as visitas são permitidas (Anzoletti et al., 2008; Clarke \& Harrison, 2001; Davidson et al., 2007; Knutsson \& Bergbom, 2007; Vint, 2005b).

Na pesquisa de Knutson et al. (2008), as crianças e os pais identificaram que ter a garantia de que o paciente está vivo, poder ver a sua condição e ter a oportunidade de expressar e compartilhar seus sentimentos são alguns dos benefícios da visita. Nos casos em que o paciente está lúcido, é possível também que a visita da criança traga alegria e sentimento de esperança para o paciente, representando um elo deste com o mundo externo (Johnson, 1994; Vint, 2005b), algo que pode auxiliar os pacientes a se sentirem seguros (Hupcey, 2000). Dessa forma, esta pode ser uma experiencia benéfica para a crianca e para o familiar internado,-se o processo for bem conduzido por profissionais da equipe de saúde e por familiares (Kean, 2009, 2010; Knutsson et al., 2008; Barros, 2003). 
Os profissionais de saúde também podem apresentar dificuldade para conversar com a criança ou o adolescente sobre os problemas graves que acometem os seus familiares (Nova et al., 2005; Perosa \& Ranzani, 2008; Tates \& Meeuwesen, 2001). Perosa e Ranzani (2008) observaram, em sua pesquisa, que aproximadamente metade dos médicos entrevistados relatou que o tema "comunicação de más notícias à criança" foi abordado durante a graduação, mas somente a minoria referiu ter recebido capacitação com instruções mais específicas sobre como lidar com essas situações. Esses autores discutem a necessidade de que novas estratégias de ensino e novos conhecimentos científicos sejam contemplados nos cursos de formação em Medicina, para instrumentalizar a comunicação médico-paciente. Como exemplo, sugerem o role-playing, uma técnica de dramatização, que inclui, além do conhecimento científico, fatores de cunho ético e legal, e também fatores emocionais. Cartilhas informativas também podem ser de grande ajuda na interação da equipe/família/ criança e na comunicação sobre os aspectos da doença (Costa Jr. et al., 2001; Gabarra \& Crepaldi, 2011; Schmidt, Bolze, Gonçalves, \& Gabarra, 2013).

Gabarra e Crepaldi (2011) não restringem a discussão à educação do corpo médico e ressaltam a necessidade de educação para toda a equipe de saúde, embora também reconheçam que são poucos os cursos na área da saúde que capacitam os futuros profissionais para esta atividade específica. As autoras destacam que a aprendizagem sobre psicologia do desenvolvimento pode auxiliar na comunicação com as crianças, na forma de lidar com o conteúdo expresso por elas e no relacionamento da equipe, não somente com as crianças, mas também com os demais familiares.

Knutsson et al. (2004) analisaram os dados de 56 enfermeiros-chefes de diferentes Unidades de Terapia Intensiva (UTIS) da Suécia, que aceitaram participar da pesquisa em relação às recomendações sobre as visitas das crianças aos pacientes internados nestas unidades. Eles observaram que, das 56 UTIs pesquisadas, somente uma instituição contava com uma política específica, ou seja, com recomendações por escrito que eram transmitidas aos familiares, juntamente com orientações verbais, acerca da visitação de crianças na unidade. E, em 16 UTIs (28\%), as recomendações eram repassadas apenas verbalmente, de forma que $70 \%$ das instituições pesquisadas não continham qualquer recomendação específica quanto à essa situação.

Outras pesquisas (Ramos et al., 2014; Gibson et al., 2012; Anzoletti et al., 2008; Vint, 2005a; Vint, 2005b; Knutsson et al., 2004) indicam que as políticas de visitação para crianças não são frequentes nas UTIs de alguns países, como Brasil, Suécia, Itália e Reino Unido. Essa omissão não significa que a equipe tenha falhado em reconhecer as necessidades das crianças que desejam visitar os adultos internados na unidade, mas representa a carência de um plano de ação nesses casos (Vint, 2005a) e pode estar contribuindo para o despreparo dos profissionais para lidar com a 'inesperada' visita das crianças (Gibson et al., 2012).

Borges et al. (2010) ressaltam alguns aspectos que devem ser avaliados no processo de tomada de decisão a respeito da entrada ou não de uma criança para visitar um familiar internado em UTI. São alguns destes: i) a motivação da criança para visitar o paciente; ii) a condição clínica do paciente e sua gravidade; iii) o grau de parentesco e qualidade da relação afetiva entre a criança e o paciente; iv) a maturidade emocional da criança e seu entendimento sobre o processo de doença e internação, e v) a rede de apoio familiar. 
Na maioria das unidades pesquisadas por Knutsson et al. (2004), esta decisão era usualmente tomada pelos enfermeiros, considerando as circunstâncias individuais, quando eles discutiam a situação entre si antes de decidir. Em apenas oito das 56 UTIs pesquisadas (14\%), essa decisão cabia exclusivamente à família. Outra pesquisa realizada com 30 pais, que tiveram os filhos visitando um familiar internado em UTI adulto, apontou que, na maioria dos casos, as crianças não tiveram qualquer acompanhamento por parte da equipe e a responsabilidade em oferecer a informação adequada às crianças ficou com os próprios pais (Knutsson \& Bergbom, 2007).

O preparo psicológico para a visita é ressaltado, destacando-se a importância de oferecer informações adequadas sobre o ambiente físico da UTI e sobre a condição e a aparência do paciente, bem como a capacidade dele para falar, ouvir, compreender e responder suas dúvidas, antes, durante e após a visita (Vint, 2005a; Vint 2005b; Knutsson, Otterberg \& Bergbom, 2004; Rozdilsky, 2005; Knutssom et al., 2008; Kean, 2010; Clarke \& Harrison, 2001; Johnson, 1994; Knutsson \& Bergbom, 2007; Barker, Nieswiadomy \& Arnold, 1998).

A observação participante da autora (ocorrida durante a inserção na rotina da UTI, no período em que foi acadêmica do Programa de Residência Integrada Multiprofissional em Saúde/Universidade Federal de Santa Catarina) e as contribuições da literatura (Gibson et al., 2012; Knutsson \& Bergbom, 2007; Knutsson et al., 2004; Clarke \& Harrison, 2001; Johnson, 1994; Hupcey, 2000) permitem pressupor que a entrada de crianças e adolescentes para visitar seus familiares adultos internados em UTI desperta opiniões distintas na equipe de saúde e nos familiares envolvidos, principalmente no que diz respeito à tomada de decisão e ao manejo desta entrada, sem causar danos emocionais à criança, o que contribui para a indefinição de regras específicas para conduzir essas situações.

Tendo em vista que conhecer os envolvidos nesse processo é essencial para subsidiar a construção de protocolos de intervenção, este estudo teve por objetivo identificar a vivência dos familiares em relação à tomada de decisão e ao manejo de entrada de crianças e adolescentes em UTI adulto.

\section{Método}

A abordagem deste estudo é qualitativa, exploratória e descritiva. O estudo ocorreu em um hospital público da Região Sul do Brasil, que possui uma UTI Adulto com 14 leitos e conta com uma equipe composta por profissionais da medicina, enfermagem, nutrição, psicologia, assistência social, fisioterapia e fonoaudiologia. Na UTI, são permitidas visitas de maiores de 12 anos, entretanto ocorre flexibilização para entradas de menores de 12 anos, conforme a condição clínica do paciente, a avaliação da equipe de saúde e a avaliação/acompanhamento do Serviço de Psicologia.

Participaram da pesquisa, 10 familiares adultos, que visitaram seus entes internados na UTI. Todos os familiares internados possuíam, na família, crianças ou adolescentes com vínculo afetivo com o familiar internado. Foram excluídos os familiares dos pacientes que evoluíram para óbito, durante a internação. Destaca-se que, para a participação na pequisa, tais crianças e adolescentes da família não precisavam ter visitado o familiar na UTI.

Os participantes foram convidados a participar deste estudo logo após o seu familiar ter recebido alta da UTI e ser transferido para a internação na enfermaria desta 
mesma instituição. Os participantes aceitaram participar da pesquisa e assinaram o Termo de Consentimento Livre e Esclarecido (TCLE). A pesquisa foi aprovada pelo Comitê de Ética em Pesquisa com Seres Humanos da Universidade Federal de Santa Catarina (CAAE: 15286313.7.0000.0121).

O instrumento de investigação para a coleta de dados foi uma entrevista semiestruturada, elaborada pelas autoras para este estudo. A entrevista foi constituída por um roteiro com os temas sobre a comunicação com a criança e o adolescente acerca do adoecimento e internação hospitalar do paciente; o processo de decisão sobre a visitação da criança e do adolescente, e a forma como lidaram com a situação.

A coleta de dados ocorreu nos meses de outubro e novembro de 2014 , e as entrevistas foram realizadas em local reservado, dentro da própria instituição, tendo sido gravadas em áudio e, posteriormente, transcritas de forma literal. O tempo médio de duração das entrevistas foi de 26 minutos e o número de participantes foi estabelecido por saturação de conteúdo.

Os dados coletados foram analisados qualitativamente utilizando-se a proposta de análise de conteúdo de Bardin (2009), a qual se caracteriza pela seleção dos núcleos de sentido que compõem a comunicação, cuja presença ou frequência possuam significado dentro do objetivo proposto. Esta análise é realizada em três etapas: i) pré-análise; ii) exploração do material, e iii) tratamento dos resultados, inferência e interpretação.

\section{Apresentação e discussão dos resultados}

A identificação dos participantes e suas características quanto às variáveis gênero, idade e relação com o paciente estão apresentadas na Tabela 1, a seguir.

\section{Tabela 1}

Apresentação das características dos participantes relativas a sexo, idade e relação com o paciente internado na UTI

\begin{tabular}{cccc}
\hline Participante & Sexo & Idade & Relação com o paciente \\
\hline F1 & Feminino & 60 & Esposa \\
F2 & Feminino & 30 & Esposa \\
F3 & Feminino & 26 & Filha \\
F4 & Feminino & 30 & Filha \\
F5 & Masculino & 41 & Esposo \\
F6 & Feminino & 30 & Esposa \\
F7 & Feminino & 72 & Esposa \\
F8 & Masculino & 35 & Esposo \\
F9 & Feminino & 75 & Esposa \\
F10 & Feminino & 48 & Esposa \\
\hline
\end{tabular}

Fonte: Elaborado pela autora com base nos dados da pesquisa.

Na Tabela 1, observa-se que a maioria dos participantes foi composta de mulheres (8) e que a relação de parentesco prioritária era de cônjuges (8), sendo dois maridos e seis esposas. Os participantes homens tinham idades entre 35 e 41 anos, e as mulheres, de 26 a 75 anos, sendo que, destas, quatro participantes possuiam idades entre 26 e 30 anos, duas na 
faixa etária de 48 a 60 anos, e duas com idade superior a 70 anos. O predomínio de familiares mulheres como visitantes e acompanhantes no contexto hospitalar corrobora com a literatura sobre a presença feminina no quer tange à função de cuidado hospitalar e domiciliar (Cristo, 2012).

Da análise dos dados, emergiram quatro categorias: i) Comunicação com a criança e o adolescente; ii) Tomada de decisão sobre a visita; iii) Manejo da visita, e iv) Repercussões da visita.

\section{Comunicação com a criança e o adolescente}

Em relação à primeira categoria, Comunicação com a criança e o adolescente, observou-se que a maioria dos participantes (F1, F2, F3, F4, F5, F6, F7, F9, F10) explicitou a importância de estabelecer uma comunicação aberta com a criança e o adolescente, evidenciando os aspectos do adoecimento e da hospitalização. A comunicação aberta, segundo Bowen (1998), seria a comunicação existente em relacionamentos nos quais o indivíduo está livre para comunicar seus pensamentos internos, sentimentos e fantasias para o outro, e este é capaz de um comportamento recíproco. O trecho a seguir ilustra a explicação do participante F2 sobre a comunicação clara e honesta realizada com as crianças.

Nós contamos tudo ... Eu contei que o pai tinha ido lá para a recuperação quando ele saiu da cirurgia porque ele ainda estava correndo risco que o médico falou que ele ia ficar lá para se recuperar um dia ele falou e logo ele ia para o quarto. Ai eu falei para ele e ele ficou contente. Eu abri o jogo com os dois, eles precisam saber tudo (F2 para os filhos de 8 e 12 anos).

No entanto, apesar de a maioria dos familiares ter contado sobre a doença e o hospital, a forma que cada um encontrou para se comunicar com a criança ou o adolescente variou de acordo com a capacidade de compreensão que eles imaginavam que a criança ou o adolescente teriam, e com a história de cada família. Foi possível observar que a quantidade de detalhes contidos na explicação fornecida pelo familiar F10 aumentou de acordo com a idade dos envolvidos.

Com a minha [filha], a de 15 [anos] eu não escondo nada dela, eu estou passando tudo que os médicos passam pra mim, eu estou passando pra elas, até porque elas são filhas ... Mas assim, com relação aos netos, que são crianças, a gente passa assim, que o avô tá doente, que o avô foi lá no hospital tomar um sorinho, daqui a pouco já fica bom e vem pra casa (F10 se referindo as diferenças na forma de comunicação com a filha de 15 anos e com os netos de 1, 4 e 10 anos).

A exclusão das crianças na comunicação sobre a doença foi evidenciada em diferentes pesquisas (Gabarra \& Crepaldi, 2011; Nova et al., 2005; Armelin et al., 2005; Oliveira et al., 2004). De acordo com a pesquisa de Gabarra e Crepaldi (2011), esse aspecto pode estar relacionado com o fato de que as crianças em idade escolar aparentam ter mais condições de compreensão sobre o adoecimento do que as pré-escolares, de forma que isso pode colaborar para que os profissionais não façam tanto investimento na comunicação com as crianças desta faixa etária.

Constatou-se que todos os participantes organizaram o conteúdo e a forma da comunicação com as crianças ou os adolescentes baseados naquilo que acreditavam ser a melhor 
forma de garantir a compreensão do significado das informações fornecidas, sem causar danos emocionais aos mesmos. O exemplo ilustra a estratégia utilizada por um dos participantes para garantir isso.

A gente passa por alto assim, a mãe está bem assim e deixa eles absorverem, se eles fizerem mais alguma pergunta a gente respeita e responde, se não a gente deixa, até pra não apavorar assim. Nunca falamos apavorando assim, tipo dizendo:- Não, ela não tem mais jeito (F5 se referindo a comunicação acerca da gravidade da situação clínica da paciente com os filhos de 7, 14 e 15 anos).

Neste trecho, observou-se o cuidado do familiar ao se comunicar com a criança e com os adolescentes, destacando a importância de transmitir segurança e esperança. Ressalta-se também que as informações foram passadas com cautela, aos poucos, oferecendo o tempo necessário para que as informações pudessem ser absorvidas e compreendidas, aspectos já mencionados em outros trabalhos (Lima \& Kovacs, 2011; Gabarra \& Crepaldi, 2011).

Apenas um participante (F8) desta pesquisa não contou para seu filho de três anos sobre o processo de hospitalização da mãe. Todavia, assim como no caso dos outros participantes, observou-se que, quando ocorreu distorção, omissão ou restrição de algumas informações por parte do familiar, estes comportamentos tiveram por objetivo proteger a criança, evitando um possível impacto negativo na vida e no comportamento da criança, bem como podem indicar a dificuldade do adulto em enfrentar a situação.

Eu nem comento muito pra ele, eu só digo pra ele que eu e a mãe fomos passear. Porque quando eu chego em casa eu digo: - Eu e mãe voltamos de passear. Ele só vê o ferimento na barriga. A gente diz que a mãe caiu e machucou. Ai ele fala a mamãe dodói e bota a mão e olha. Ai a gente diz: - Ó tu tem que cuidar, porque tu é pequeno, se cair vai machucar. Ele é pequeninho pra entender. (F8 se referindo a comunicação com o filho de 03 anos).

Este controle do acesso da criança à informação, quando um de seus familiares está internado na UTI, pode estar associado à compreensão dos pais de que a proteção da criança é sua função e, dessa forma, tentam protegê-la do possível sofrimento desencadeado pelo contato com esse tipo de informação (Kean, 2009). No entanto, conforme apresentado no relato do participantes $\mathrm{F} 8$, mesmo sem que o processo de adoecimento seja verbalizado para a criança, a mesma está atenta ao que acontece à sua volta, o que pode nem sempre ser percebido e reconhecido pelo adulto (Kean, 2009; Castro \& Piccinini, 2002), que pode se esquivar de explicar o que está acontecendo para a criança ou conta a ela mentiras (Sengik \& Ramos, 2013). Em ambos os casos, na tentativa de poupá-la, o adulto a deixa insegura, já que ela é capaz de perceber as expressões não verbais, as expressões entristecidas e até o silêncio, como sinais de que as coisas não estão bem com o seu familiar (Sengik \& Ramos, 2013; Rozdilsky, 2005; Torres, 1999).

A capacidade da criança em perceber a mudança na rotina familiar e de prestar atenção nas conversas do adulto, captando o que acontece à sua volta, foi ressaltada por participantes desta pesquisa (F1, F3, F5, F9, F10) e foi um dos aspectos que contribuíram para que a criança fosse incluída na comunicação familiar acerca do adoecimento e da hospitalização, conforme apresentado no fragmento a seguir. 
... (ele percebe) até porque mudou toda a nossa rotina. Eu tenho que levar ele no colégio, aí tenho que arranjar alguém que busque, porque antes era minha mãe que fazia essa função de buscar pra mim ou meu pai buscava, ficava esse horário. Aí tem todo um planejamento diferente. Aí ele percebe, aí a gente conversa, explica pra ele (F3 se referindo ao filho de 7 anos que é neto do paciente e residia com o mesmo).

Um dos participantes (F5) reconheceu o papel, já destacado por Barros (2003), que a comunicação aberta com crianças e adolescentes tem em seu desenvolvimento, destacando que é importante informá-los constantemente e deixá-los a par das mudanças que estão ocorrendo, pois isso facilitaria sua compreensão e adaptação, caso a situação clínica se agrave. Em suas próprias palavras:

Acho que é interessante ir falando, porque depois, se acontece alguma coisa, eles já tão mais preparados, de uma maneira ou de outra já está havendo uma preparação, olha a mãe tá doente, não está bem, está isso ou não está, depois se acontece alguma coisa mais grave eu acho que eles vão estar um pouco mais fortes pra conseguir aceitar. Saber o que levou a acontecer (F5 se referindo aos filhos do paciente de 7, 14 e 15 anos).

A possibilidade de postergar ou prejudicar o desenvolvimento emocional da criança, devido à ausência de comunicação sobre o processo de adoecimento com a criança, também foi ressaltado por Rozdilsky (2005). Nesse sentido, a comunicação com a criança precisa ser aberta e clara, e as explicações do adulto devem corresponder à verdade, adequando-se a capacidade cognitiva e intelectual da criança (Lima \& Kovacs, 2011; Schmidt et al., 2013).

A dificuldade na comunicação com a criança não é exclusiva dos pais. Estudos abrangendo pacientes pediátricos constataram também as dificuldades da equipe de saúde em relação à comunicação com a criança (Nova et al., 2005; Perosa \& Ranzani, 2008; Tates \& Meeuweesen, 2001). Este fato pode estar relacionado à falta de capacitação oferecida aos profissionais durante e após a graduação acadêmica (Perosa \& Ranzani, 2008), e a abordagem de questões relativas à psicologia do desenvolvimento poderia contribuir, nesse sentido (Gabarra \& Crepaldi, 2011).

Ainda em relação à comunicação, os participantes destacaram os motivos pelos quais consideram importante conversar com as crianças e os adolescentes, pois metade deles (F1, F2, F4, F5, F6) ressaltou a curiosidade das crianças e dos adolescentes como principal fator que motivou a comunicação acerca do adoecimento e da hospitalização. O trecho a seguir ilustra a manifestação do desejo da criança em obter informações sobre o que está acontecendo:

Porque ele não vê, a gente comentou que o pai estava na UTI e ele não viu, daí ele fica sempre pedindo como que o pai ficou lá. ... Os dois, mais o de 8 pergunta mais, esse pequeno sempre faz mais perguntas (F2 em relação aos filhos de 8 e 12 anos)

Neste último trecho, percebe-se que a criança demonstrou mais curiosidade que o adolescente. Já na perspectiva de outro participante (F5), apresentada a seguir, é a filha mais velha quem pergunta e deseja saber mais.

A outra, que tem 15 anos, ela já consegue entender um pouquinho mais qual é a gravidade do problema, do que é que pode acontecer, acontecer alguma coisa e eu posso perder minha mãe, então ela sempre quer um pouco mais de informação, o que está acontecendo (F5 em relação aos filhos de 7, 14 e 15 anos). 
Estes relatos salientam que a idade não deve ser o único fator a nortear a quantidade ou o conteúdo das informações compartilhadas com a criança ou o adolescente, pois, em cada situação, existirão diferentes necessidades a serem satisfeitas, de acordo com as características individuais e familiares dos envolvidos. A forma como as crianças e os adolescentes vivenciam a doença grave e as suas estratégias para o acesso às informações são influenciadas pela dinâmica comunicacional existente nas famílias. Quando a criança é incluída na comunicação familiar e participa da decisão de visitar ou não o familiar internado na UTI, ela está no controle de sua própria necessidade de informação, pois ela tem a oportunidade de perguntar diretamente aos familiares e consultar os profissionais de saúde. Nos casos em que a criança não recebe as informações acerca do que está acontecendo em relação ao processo de adoecimento e internação de um familiar, ela própria encontra estratégias para buscar a informação de que necessita, ressaltando que as crianças não são passivas, mas ativamente construtoras e co-construtoras de suas próprias experiências (Kean, 2009).

Os relatos dos participantes apresentaram diferenças quanto à forma como a situação da visita foi conduzida pela equipe, o que pode indicar que a instituição referida não possui recomendações específicas ou que essas orientações, caso existam, não tenham sido repassadas de maneira clara para os participantes. A falta de políticas e diretrizes claras a serem seguidas em relação à visita de crianças e adolescentes no contexto de UTI também é ressaltada em outros estudos (Ramos et al., 2014; Gibson et al., 2012; Anzoletti et al., 2008; Vint, 2005a; Vint, 2005b; Knutsson, Otterberg, \& Bergbom, 2004).

\section{Tomada de decisão sobre a visita}

Em relação à segunda categoria, Tomada de decisão sobre a visita, verificou-se que esta decisão foi influenciada por quatro aspectos, dois dos quais já mencionados por Borges et al. (2010). Foram considerados pelos familiares: i) o desejo da criança ou do adolescente de ir visitar; ii) o estado clínico do paciente; iii) o imaginário de que a visita de crianças não é permitida em UTI, e iv) o posicionamento da equipe.

Foi possível constatar que cada um destes aspectos teve um peso diferente para cada participante e que a inter-relação entre estes, em conjunto com a história de vida pessoal e familiar, contribuiu para a ocorrência ou não da permissão para crianças e adolescentes visitarem o familiar internado na UTI.

A Tabela 2, a seguir, indica quais crianças e adolescentes foram visitar os seus familiares durante a internação em UTI.

\section{Tabela 2}

Apresentação das características dos familiares crianças e adolescentes dos participantes entrevistados e a descrição de quais foram visitar o seu familiar na UTI

\begin{tabular}{cccc}
\hline Familiar & $\begin{array}{c}\text { Crianças ou adolescentes na família e } \\
\text { sua relação com o paciente }\end{array}$ & $\begin{array}{c}\text { Foram visitar } \\
\text { na UTI }\end{array}$ & $\begin{array}{c}\text { Relação com o } \\
\text { paciente (idade) }\end{array}$ \\
\hline F1 & Netas $(1,1,11,12$ anos) & Sim & Neta (11 anos) \\
F2 & Filhos $(8,12$ anos $)$ & Não & - \\
F3 & Neto (7 anos) & Não & - \\
F4 & Filho (8 anos); Neto (1, 4 anos) & Não & -
\end{tabular}




\begin{tabular}{cccc}
\hline Familiar & $\begin{array}{c}\text { Crianças ou adolescentes na família e } \\
\text { sua relação com o paciente }\end{array}$ & $\begin{array}{c}\text { Foram visitar } \\
\text { na UTI }\end{array}$ & $\begin{array}{c}\text { Relação com o } \\
\text { paciente (idade) }\end{array}$ \\
\hline F5 & Filhos $(7,14,15$ anos); Sobrinha (10 anos) & Sim & Filhos (10, 14, 15 anos) \\
F6 & Filho (8 anos) & Não & - \\
F7 & Netos $(14,15,16$ anos $)$ & Sim & Netos $(14,15,16$ anos) \\
F8 & Filho (3 anos) & Não & $=$ \\
F9 & Netos $(15,16,17$ anos $)$ & Sim & Neta (15 anos) \\
F10 & Filha (15 anos); Netos $(1,4,10$ anos) & Sim & Filha (15 anos) \\
\hline
\end{tabular}

Fonte: Elaborado pela autora com base nos dados da pesquisa.

Foi possível observar, no relato de um dos participantes (F5), que o estado clínico do paciente foi o aspecto central da decisão pelo melhor momento para ocorrer a entrada da adolescente na UTI. O participante relata que preferiu aguardar a estabilização do quadro para não correr o risco de seus filhos de 14 e 15 anos presenciarem o momento do óbito em si. Considerando-se o estado clínico do paciente durante a internação em UTI e a previsão de alta, alguns participantes (F3, F6) optaram por restringir a visita na UTI e permití-la durante a internação nas enfermarias, ambiente que foi considerado por eles como mais tranquilo, apresentando o horário e as regras de visitação mais flexíveis. Um deles (F3) informou que, se o tempo de internação se prolongasse, provavelmente solicitaria a entrada do neto mesmo na UTI, tendo em vista o vínculo afetivo entre eles. Outros três participantes (F2, F8, F10) informaram que sempre imaginaram que a visita de crianças não era permitida em nenhum ambiente do hospital, mas que, durante o período em que passaram acompanhando o paciente, dois deles (F2 e F8) observaram que essa visita era permitida nas enfermarias.

O ambiente de UTI é percebido nos relatos dos participantes como mais aversivo do que o restante do ambiente hospitalar, provavelmente por ser um ambiente constantemente associado à morte. A própria estrutura física da UTI é diferenciada, os leitos são abertos e cada paciente tem menos privacidade, o que faz com que a pessoa, ao ir visitar seu familiar internado, depare-se com outros pacientes em estado grave. Este foi um aspecto considerado pelos participantes para evitar a visita da criança na UTI e preferir aguardar a alta para outra enfermaria.

Independentemente de a visita ser permitida ou não, Vint (2005a) ressalta algumas estratégias que podem ser efetivadas para reduzir o estresse das crianças e auxiliar na manutenção da comunicação e do vínculo com o familiar que está internado em UTI. A escrita de bilhetes ou cartas, a confecção de desenhos e a escolha de fotos, por parte da criança, que podem ser levados para o paciente internado até mesmo por outro visitante e deixados no leito podem ser alguns exemplos de comunicação e de integração da criança com a situação vivenciada pela família (Vint, 2005a).

Observou-se que o desejo expresso pela criança ou pelo adolescente para ir visitar o familiar na UTI foi influenciado pelo vínculo afetivo existente entre a criança e o familiar que estava internado. Um dos participantes (F9) relatou que este foi o principal aspecto considerado para permitir a entrada da adolescente de 15 anos na UTI, conforme se pode perceber no trecho a seguir:

E aquela de 15 anos [dizia], ah mas eu gostava de ver o avô, eu gostava de ver o avô, então vamos lá minha filha e tu vê o avô. Ela que quis ir ver o avô. . . . Aí a gente achou 
que era importante ela vim porque era o desejo dela, né?. Então a gente respeitou o desejo dela (F9 se referindo a neta do paciente de 15 anos).

No entanto, para este mesmo participante (F9), imaginar que a visita de crianças não seria permitida foi o aspecto decisivo na tomada de decisão em relação aos netos, conforme ilustrado no trecho a seguir.

As crianças não foram visitar. Só a Juliana que foi. Não pesou nada assim porque, a princípio a gente sabe que não pode (F9 se referindo a filha Juliana de 15 anos e aos netos de 1,4 e 10 anos).

Para outros dois participantes (F2 e F4), o estado clínico do paciente e a falta de informações tiveram maior peso na decisão, contribuindo para que a visita não acontecesse, apesar do desejo manifesto pela criança de visitar o familiar na UTI. Nesses dois casos, os pacientes tinham perspectiva de melhora e posterior alta da UTI, e como já imaginavam que a visita não seria permitida, não chegaram a buscar informações junto à equipe e nem chegaram a cogitar levar seus filhos ou netos para visitar o familiar internado.

O relato a seguir aponta que, apesar da insistência do filho em querer ver o pai durante a internação na UTI e do desejo da mãe (F6), esta visita não foi permitida pela equipe. No entanto, neste mesmo trecho é possível observar uma exceção, momento em que a equipe permitiu a entrada de uma criança.

Eu cheguei a perguntar [para a equipe], comentei assim e [eles responderam que]- não, aqui em cima não. ... Só nos últimos casos, que nem aconteceu com um paciente que aí estava nas últimas, daí aquele foi autorizado, mas como ele não era daqueles problemas, aí eles disseram que não podia (F6)

Outros três participantes (F1, F5 e F10) solicitaram a entrada de crianças e apenas um (F1) obteve a autorização da equipe. Outro participante (F5) informou uma situação na qual a equipe abriu uma exceção para a entrada de uma criança, conforme o relato a seguir.

A de sete [anos] não foi, até porque já é uma norma da casa que não pode. . . . A gente chegou a perguntar, mas aí orientaram que não, até naquele momento que ela estava com a traqueo, que ela estava bem mal. Então a gente até fez a pergunta e eles disseram que não, que não dava. . . . Até teve uma exceção que eles abriram pra minha sobrinha de 10 anos que ia fazer a primeira comunhão e é afilhada dela que ela queria ir lá pedir a benção dela e ela foi lá e pediu a benção e eles até abriram uma exceção. (F5)

Observou-se, a partir dos relatos apresentados, que a equipe teve papel importante na tomada de decisão dos participantes. Foi possível verificar também que, para além da idade, existem outros critérios que foram considerados pela equipe no momento de autorizar ou não a entrada de uma criança na UTI. Além disso, o discurso destes participantes pode indicar que não existe consenso a respeito das recomendações entre os profissionais que atuam nesta unidade. Outro estudo apontou que a decisão acerca da visita é considerada pela equipe a partir de circunstâncias individuais e que nem sempre existe consenso entre os membros da equipe em relação à temática (Knutsson et al., 2004), enquanto, em outra pesquisa, a tomada de decisão, na maior parte das vezes, coube aos pais (Knutsson \& Bergbom, 2007). 
Além dos fatores que contribuíram para o seu posicionamento e para a tomada de decisão quanto à entrada das crianças e dos adolescentes na UTI, os cinco participantes que levaram crianças e adolescentes para visitar os pacientes internados (F1, F5, F7, F9, F10) relataram a forma como manejaram esta entrada.

\section{Manejo da visita}

Sobre a terceira categoria, Manejo da visita, todos os participantes mencionaram a importância de preparar a criança e o adolescente antes da realização da visita, fornecendo as informações acerca do ambiente da UTI e do estado clínico do paciente. A responsabilidade dos pais em preparar as crianças para a visita, fornecendo informações apropriadas a elas, também foi relatada por Knutsson e Bergbom (2007).

A preocupação dos familiares em preparar a criança e o adolescente para o momento da visita pode ser ilustrada com o trecho a seguir.

A gente tinha contado que o vô estava intubado e que o vô não falava e que o vô não abria os olhos, as vezes ele abria um olho um pouquinho, ela sabia tudo. Ela sabia a imagem que ela ia ver ali, a gente preparou ela pra ver se ela queria mesmo, mas ela queria

(F7 se referindo a neta de 15 anos).

Este relato vai ao encontro dos resultados da pesquisa de Knutsson, Otterberg e Bergbom (2004), em relação às diretrizes sobre como oferecer suporte e informações para as crianças. Somente uma participante (F10) não preparou a adolescente antes da entrada em UTI e percebeu a importância deste procedimento após a visita já ter ocorrido, pois verificou os efeitos negativos de a visita acontecer sem que a adolescente tenha sido orientada a respeito da forma como o paciente estava, conforme apresentado no trecho a seguir.

Então assim, ela deveria ser preparada, o psicológico dela, o emocional, assim:- ó o avô vai tá assim ... Não foi feito nenhum tipo de conversa com ela [filha] antes, a gente contou pra ela que ele estava na UTI e ela falou que queria ver o pai ali e aí eu disse que à tarde ela ia então. Aí foi tranquilo, ela entrou, aí ela estava bem, aí quando ela chegou lá dentro, ela retornou aos prantos chorando. Acho que faria alguma diferença se a gente tivesse falado com ela antes, até porque ela sabe como que o pai dela tá e eu acho que o que chocou ela foi ter visto o pai dela conectado naquelas coisas todas. Ela não estava esperando ver ele daquele jeito. (F10 em relação a filha do paciente de 15 anos).

A clareza quanto às recomendações para a visita de crianças e adolescentes para os familiares, e a padronização na forma de orientar os familiares sobre isso poderiam auxiliar a evitar que situações como a relatada anteriormente aconteçam. Nesse sentido, Vint (2005a) sugere o desenvolvimento de informação escrita específica para os pais ou responsáveis pela criança e, também, materiais informativos exclusivos e adequados à idade das crianças. Além disso, considerando-se que as crianças são uma parte importante da unidade familiar, o ambiente precisa estar adequado a elas. Nesse sentido, a provisão de materiais lúdicos, como brinquedos, material para desenho e livros infantis, dentro de uma sala de espera, poderia auxiliá-las a sentirem-se parte integrante da família e bem-vindas nesse ambiente, considerado tão hostil (Vint, 2005a, Vint 2005b; Knutsson et al., 2004). A situação relatada pelo participante (F10) envolve um adolescente, evidenciando a necessidade de ampliação 
da discussão proposta por Vint (2005a), para incluir os adolescentes. Eles também sofrem o impacto de ter um familiar internado em UTI e devem receber o suporte necessário e adequado à sua capacidade de compreensão, para enfrentar e elaborar a experiência da visita da melhor forma possível.

Segundo alguns participantes (F1, F5, F7, F9, F10), a entrada das crianças ou dos adolescentes foi sempre acompanhada da presença de um familiar adulto. Após a visita, três deles (F1, F5, F9) afirmaram ter conversado sobre a visita em si e oferecido o apoio necessário, considerando as repercussões que eles perceberam nas crianças e nos adolescentes ao visitar, pois, mesmo com a preparação, essa situação se mostrou difícil, como apontado na literatura (Borges et al., 2010; Knutsson et al., 2004).

O que eles comentam quando eles veem que ela tá mais ruinzinha, o que eles comentam é que preferiam não ter visto.- Preferia não ter visto a mãe dessa forma.- Eu já tinha avisado que ela não estava tão benzinha, eu preparei, mas mesmo assim o comentário dos dois foi assim ... Mas quiseram voltar num outro dia (F5 a respeito dos filhos de 14 e 15 anos).

\section{Repercussões da visita}

A quarta categoria se refere às Repercussões da visita. O misto de tristeza e alegria no momento da visita, apresentado no relato do familiar, também foi percebido em outros estudos pelos pais de crianças que visitaram seus familiares internados na UTI (Knutsson et al., 2008; Knutsson \& Bergbom, 2007). Ainda em relação às repercussões da visita, dois participantes (F1, F10) relataram que a forma como a criança ou o adolescente reagiu dependeu do vínculo estabelecido com o paciente e de como ele participava da dinâmica familiar.

. . . por causa da ausência de não estar tanto com o avô que ela [neta de 18 anos] se emocionou mais. Então a outra [neta de 11 anos], como estava sempre com o vô, ela já sabia que ele estava sofrendo em casa e que estava ali [no hospital] para melhorar. Então acho que foi melhor (F1 se referindo às diferentes reações entre as netas de 11 e 18 anos).

Além disso, certos participantes (F5, F7, F9, F10) destacaram os benefícios da visita realizada para o paciente e também para as crianças e os adolescentes.

Poder ver quem ela ama ... E na UTI eu acho que depende muito do estado do paciente né?, mas eu acho que é confortável pra ambos, tanto pra quem tá com saudade de ver e até para o próprio paciente pra dar aquela renovada né? Acho que isso ajuda a recuperação do paciente, o contato com o filho, com o neto, um sobrinho, seja lá o que for né? (F5)

Os benefícios da visita de crianças e adolescentes nesse contexto já foram apontados em outros trabalhos (Anzoletti et al., 2008; Clarke \& Harrison, 2001; Davidson et al., 2007; Knutsson \& Bergbom, 2007; Vint, 2005b; Hupcey, 2000; Johnson, 1994). Um dos participantes (F10) comentou ainda que acredita que a visita terá efeito positivo também em longo prazo na vida da neta, pois a auxiliará a enfrentar futuras situações semelhantes. 
Ela [a neta] sabia que ela podia entrar e ela quis entrar, ela queria, ela que falou que queria tá lá dentro e foi tranquilo assim. Eu concordei porque eu penso assim, a gente tem que viver a situação do momento, mesmo não tendo preparado a gente tem que viver aquilo ali. Eu vou podar ela de passar ela por aquele período ali, aí lá na frente aí tem que passar uma outra situação parecida e ela não estava preparada porque nessa situação ela não passou por esse momento agora (F10).

No entanto, permitir a visita, por si só, não garante a diminuição da ansiedade e a prevenção de traumas futuros. Pesquisas apontam que possibilitar a visita sem oferecer um acompanhamento profissional e familiar adequado para a criança pode ser tão nocivo quanto impedir que a visita aconteça (Rozdilsky, 2005; Vint, 2005b; Knutssom et al., 2008).

Conhecer as particularidades de cada criança e a forma como cada uma compreende o que está acontecendo pode auxiliar a prevenir futuros traumas, na medida em que as informações e explicações acerca do que ela irá encontrar no ambiente da UTI sejam oferecidas em uma linguagem acessível à sua compreensão (Kean, 2010; Clarke \& Harrison, 2001; Johnson, 1994; Knutsson \& Bergbom, 2007; Rozdilsky, 2005; Knutsson et al., 2004; Barker et al., 1998).

É necessário explicar para a criança o que está acontecendo à sua volta, deixar que seus pensamentos, opiniões e vozes sejam ouvidos, e permitir-lhes alguma parte nas decisões sobre aquilo que pode afetá-las (Knutsson et al., 2004). No entanto, a supervisão, o acompanhamento e o apoio emocional devem ser oferecidos não somente antes, mas também durante e após as visitas de crianças (Borges et al., 2010; Vint, 2005a; Knutsson et al., 2004; Knutsson \& Bergbom, 2007). Vint (2005a) sugere que um projeto de pesquisa-ação poderia auxiliar nessas situações, assim como outras pesquisas poderiam ser realizadas para avaliar os efeitos em curto e longo prazo, seus riscos e benefícios para os pacientes e para as crianças que passaram por tal experiência.

O estabelecimento de políticas e diretrizes claras nas instituições, assim como a preparação específica dos profissionais acerca da visita de crianças, poderiam contribuir para uma assistência humanizada e de qualidade (Knutsson et al., 2004). As práticas precisam ser desenvolvidas baseadas em evidências, para promover uma abordagem coerente da equipe com o objetivo de satisfazer às necessidades das crianças que visitam um familiar internado em UTI adulto (Vint, 2005a; Knutsson et al., 2004).

\section{Considerações finais}

Os familiares identificaram a capacidade que crianças e adolescentes têm em perceber as mudanças que ocorrem na família, em virtude da hospitalização de um de seus membros, bem como a curiosidades dos mesmos para saber mais informações sobre esse processo. No momento de repassar as informações acerca do adoecimento e da hospitalização em UTI para crianças e adolescentes, observaram-se o cuidado e as dificuldades dos familiares para transmitirem esperança e segurança na comunicação, com o intuito de minimizar os danos emocionais.

Para a tomada de decisão quanto à permissão ou não da visita, os familiares consideraram: o desejo da criança ou do adolescente em visitar; o estado clínico do paciente, e o posicionamento da equipe. Além disso, identificou-se que o imaginário de que a visita de 
crianças não é permitida em UTI interferiu na decisão de alguns deles. Ressalta-se a utilidade de delimitar os critérios para a visita de crianças e adolescentes aos seus familiares internados em UTI, não no sentido de desconsiderar a singularidade de cada caso ou cristalizar o procedimento, mas para estabelecer os aspectos a serem avaliados para a tomada de decisão. Os estudos relativos à psicologia do desenvolvimento podem contribuir para a compreensão dos recursos que crianças e adolescentes têm para lidar com esse tipo de situação, bem como podem auxiliar na comunicação entre os envolvidos.

A preparação psicológica antes da realização da visita foi o elemento mais citado como importante, no manejo da visita. Foi possível perceber, a partir dos resultados, que os familiares adultos também sofrem o impacto emocional negativo associado à visita em UTI, o que pode ter contribuído para sua concepção de que a visita desencadearia esse tipo de sentimentos nas crianças e nos adolescentes. E sua percepção de que crianças e adolescentes, especialmente os mais novos, não têm condições de lidar com esse tipo de situação pode estar relacionada com a dificuldade sentida por eles próprios para lidar com essa situação. A partir desta necessidade, sugere-se que sejam propostas intervenções, como, por exemplo, orientações e material informativo específico e adequado, tanto para os familiares adultos quanto para crianças e adolescentes.

Os resultados desta pesquisa destacam que o hospital, em especial a UTI, não é considerado pelos familiares um ambiente indicado para a presença de crianças, embora os benefícios da visita tenham sido mencionados. Destaca-se que esta experiência tem o potencial de contribuir para o desenvolvimento emocional das crianças, ao favorecer a compreensão do processo de adoecimento e possível morte, desde a infância, e contribuir para o enfrentamento de futuras situações de frustração, se tal abordagem for bem conduzida pela equipe e pelos familiares.

Este artigo pretende contribuir para o desenvolvimento de conhecimento científico sobre a temática, tendo em vista que são raros os estudos nacionais que contemplam a visitação de crianças e adolescentes em UTIs adulto, além de colaborar para a criação de protocolos de intervenções pautados em evidências científicas quanto à rotina de entrada de crianças em UTI adulto, visando melhorar a qualidade na assistência e obter uma maior satisfação dos envolvidos. No entanto, destaca-se ainda a necessidade de se realizarem mais pesquisas na área, com o objetivo de ouvir e buscar compreender os demais envolvidos nesse processo: crianças e adolescentes, pacientes e profissionais de saúde. Acredita-se que a divulgação do tema possa desencadear reflexões e contribuir para subsidiar práticas mais humanizadas e de qualidade, em saúde.

\section{Referências}

Anzoletti, A. B. et al. (2008). Access to intensive care units: A survey in North-East Italy. Intensive and Critical Care Nursing, 24(9), 366-374.

Armelin, C. B. et al. (2005). A comunicação entre profissionais de pediatria e a criança hospitalizada. Revista Brasileira de Crescimento e Desenvolvimento Humano, 15(2), 45-54. Bardin, L. (2009). Análise de conteúdo. Lisboa: Edições 70.

Barker, C., Nieswiadomy, R. M., \& Arnold, W. K. (1998). Nursing interventions for children with a parent in the intensive care. Heart Lung, 17(4), 441-446. 
Barros, L. (2003). Psicologia pediátrica: Perspectiva desenvolvimentalista. 2a ed. Lisboa: Climepsi Editores.

Borges, K. M. K., Genaro, L. T., \& Monteiro, M. C. (2010). Visita de crianças em unidade de terapia intensiva. Revista Brasileira de Terapia Intensiva, 22(3), 300-304.

Bowen, M. (1998). A reação da família a morte. Wash, F., \& McGoldrick, M. (Org.). Morte na familia: Sobrevivendo às perdas. Porto Alegre: Artmed.

Castro, E. K., \& Piccinini, C. A. (2002). Implicações da doença orgânica crônica na infância para as relações familiares: Algumas questões teóricas. Psicologia: Reflexão e Crítica, 15(3).

Cerveny, C. M. O., \& Berthoud, C. M. E. (2009). Ciclo vital da família brasileira. São Paulo: Casa do Psicólogo.

Clarke, C., \& Harrison, D. (2001). The needs of children visiting on adult intensive care units: A review of the literature and recommendations for practice. Journal of advanced nursing, 34(1), 61-68.

Costa Jr., A. L. et al. (2001). O uso de manuais educativos em saúde pediátrica: Um exemplo de hemofilia. Pediatria Moderna, 37(5), 190-195.

Cristo, R. de C. (2012) O acompanhante e o espaço de visita: Um estudo no Hospital Universitário de Brasília (Tese de Doutorado em Ciências da Saúde, Universidade de Brasília, Brasília-DF, Brasil).

Davidson, J. E. et al. (2007). Clinical practice guidelines for support of the family in the patientcentered intensive care unit: American College of Critical Care Medicine Task Force 20042005. Critical Care Medicine, 35(2), 605-622.

Gabarra, L. M., \& Crepaldi, M. A. (2011). A comunicação médico- paciente pediátrico-família na perspectiva da criança. Psicologia Argumento, 29(65), 209-218.

Gibson, V. et al. (2012). Position statement on visiting in adult critical care units in the UK. Nursing in Critical Care, 17(4), 213-218.

Hupcey, J. E. (2000). Feeling safe: The psychological needs of ICU patients. Journal of Nursing Scholarship, 32, 361-367.

Johnson, D. L. (1994). Preparing children for visiting parents in the adult ICU. Dimensions of Critical Care Nursing, 1(3), 152-154.

Kean, S. (2009). Children and Young People's strategies to access information during a family member's critical illness. Journal of Clinical Nursing, 19, 266-274.

Kean, S. (2010). Children and young people visiting an adult intensive care unit. Journal of Advanced Nursing, 66(4), 868-877.

Knutsson, S., \& Bergbom, I. (2007). Nurse's and physicians' viewpoints regarding children visiting/not visiting adult ICUs. Nursing in Critical Care, 12(2), p. 64-73.

Knutsson, S. E., Otterberg, C. L., \& Bergbom, I. L. (2004). Visits of children to patients being cared for in adult ICUs: Policies, guidelines and recommendations. Intensive Crit Care Nurs, 20(5), 264-274.

Knutsson, S. et al. (2008). Children's experiences of visiting a seriously ill/injured relative on an adult intensive care unit. Journal of Advanced Nursing, 61, 154-162.

Lima, V. R., \& Kovacs, M. J. (2011). Morte na família: Um estudo exploratório acerca da comunicação à criança. Psicologia Ciência e Profissão, 31(2).

Nova, C., Vegni, E., \& Moja, E. A. (2005). The physician patient-parent communication: a qualitative perspective on the child's contribution. Patient Education and Counseling, 58(3), 327-333. 
Oliveira, V. Z. et al. (2004). Comunicação do diagnóstico: Implicações no tratamento de adolescentes doentes crônicos. Psicologia em Estudo, 9(1), 9-17.

Perosa, G. B., \& Ranzani, P. M. (2008). Capacitação dos médicos para comunicar más notícias às crianças. Revista Brasileira de Educação Médica, 32(4), 468-473.

Ramos, F. J. S. et al. (2014). Políticas de visitação em unidades de terapia intensiva no Brasil: Um levantamento multicêntrico. Revista Brasileira de Terapia Intensiva, 26(4).

Rozdilsky, J. R. (2005). Enhancing sibling presence in pediatric ICU. Critical Care Nursing Clinics of North America, 17(4), 451-461.

Schmidt, B., Bolze, S. D. A., Gonçalves, J. R., \& Gabarra, L. M. (2013). Terminalidade, morte e luto em famílias com crianças e adolescentes: Possibilidades de intervenção psicológica. In A. Garcia, \& R. Díaz-Loving (Orgs.). Relações familiares: Estudos latino-americanos. Vitória: UFES.

Sengik, A. S., \& Ramos, F. B. (2013). Concepção de morte na infância. Psicologia \& Sociedade, 25(2).

Tates, K. \& Meeuweesen, L. (2001). Doctor-parent-child communication. A (re)view of the literature. Social Science and Medicine, 52(6), 839-851.

Torres, W. C. (1999). A criança diante da morte: Desafios. São Paulo: Casa do Psicólogo.

Vint, P. E. (2005a). Children visiting adults in ITU - What support is available? A descriptive survey. Nursing in Critical Care, 10(2), 64-71.

Vint, P. E. (2005b). An exploration of the support available to children who may wish to visit a critically adult in ITU. Intensive Critical Care Nursing, 21(3), 149-159.

Recebido: 22/07/2016

Última revisão: 10/08/2017

Aceite final: 12/09/2017

\section{Sobra as autoras:}

Maria Emília Pereira Nunes - Hospital Universitário - Universidade Federal de Santa Catarina. E-mail: mariaemiliapn@gmail.com

Letícia Macedo Gabarra - Hospital Universitário - Universidade Federal de Santa Catarina. E-mail: leticiagabarra@gmail.com 
